\title{
The Influence of the AMOC Variability on the Atmosphere in CCSM3
}

\author{
Claude Frankignoul and Guillaume Gastineau \\ LOCEAN, University Pierre and Marie Curie, Paris, France \\ YOUNG-OH KWON \\ Woods Hole Oceanographic Institution, Woods Hole, Massachusetts
}

(Manuscript received 28 December 2012, in final form 22 July 2013)

\begin{abstract}
The influence of the Atlantic meridional overturning circulation (AMOC) variability on the atmospheric circulation is investigated in a control simulation of the NCAR Community Climate System Model, version 3 (CCSM3), where the AMOC evolves from an oscillatory regime into a red noise regime. In the latter, an AMOC intensification is followed during winter by a positive North Atlantic Oscillation (NAO). The atmospheric response is robust and controlled by AMOC-driven SST anomalies, which shift the heat release to the atmosphere northward near the Gulf Stream/North Atlantic Current. This alters the low-level atmospheric baroclinicity and shifts the maximum eddy growth northward, affecting the storm track and favoring a positive NAO. The AMOC influence is detected in the relation between seasonal upper-ocean heat content or SST anomalies and winter sea level pressure. In the oscillatory regime, no direct AMOC influence is detected in winter. However, an upper-ocean heat content anomaly resembling the AMOC footprint precedes a negative NAO. This opposite NAO polarity seems due to the southward shift of the Gulf Stream during AMOC intensification, displacing the maximum baroclinicity southward near the jet exit. As the mode has somewhat different patterns when using SST, the wintertime impact of the AMOC lacks robustness in this regime. However, none of the signals compares well with the observed influence of North Atlantic SST anomalies on the NAO because SST is dominated in CCSM3 by the meridional shifts of the Gulf Stream/ North Atlantic Current that covary with the AMOC. Hence, although there is some potential climate predictability in CCSM3, it is not realistic.
\end{abstract}

\section{Introduction}

Much effort has been recently devoted to investigate and quantify decadal climate predictability, using coupled climate models. Most studies focus on the Atlantic meridional overturning circulation (AMOC) (Collins 2002; Pohlmann et al. 2004; Collins et al. 2006; Msadek et al. 2010) or the upper-ocean heat content (Branstator et al. 2012), which seem especially predictable and may influence climate fluctuations over the continents, being thus of particular socioeconomic interest. An influence of the Atlantic multidecadal oscillation (AMO), which has been suggested to largely result from AMOC fluctuations, on summer precipitation in North America and Europe, Atlantic hurricane activity, and other climatic

Corresponding author address: Claude Frankignoul, LOCEAN, University Pierre and Marie Curie, 4 Place Jussieu, 75005 Paris, France. E-mail: cf@locean-ipsl.upmc.fr features has been suggested by several empirical and modeling studies (e.g., Enfield et al. 2001; Sutton and Hodson 2005; Knight et al. 2006). Changes in the atmospheric circulation and a strengthening of the North Atlantic storm track have been attributed to the sustained weakening of the AMOC in most hosing and anthropogenic gas forcing experiments with climate models (e.g., Stouffer et al. 2006; Brayshaw et al. 2009; Woollings et al. 2012), but control simulations provide a cleaner setup to detect the influence of the AMOC variability on the atmospheric circulation (Msadek and Frankignoul 2009; Teng et al. 2011; Gastineau and Frankignoul 2012, hereafter GF12). However, because of the natural variability of the atmosphere, the signal-to-noise ratio is small and the predictability of the atmospheric signals associated with the natural variability of AMOC seems weak, albeit less so on decadal scales (Teng et al. 2011).

For climate forecasts to have predictive value, the relevant air-sea interactions must be realistic in climate 
models. Since the AMOC variability cannot be estimated reliably from observations over sufficiently long periods, one cannot directly assess whether the atmospheric response to the AMOC detected in a climate model is relevant to the real climate system. On the other hand, one can verify if the air-sea interactions in the model are consistent with the influence of sea surface temperature (SST) anomalies on the atmospheric circulation detected in observations at the seasonal scale, in particular in the North Atlantic sector where an AMOC impact may be expected. Gastineau et al. (2012, hereafter GDF) showed that the North Atlantic SST influence on the North Atlantic Oscillation (NAO) in L'Institut Pierre-Simon Laplace Coupled Model, version 5 (IPSL CM5), was broadly consistent with the influence of the North Atlantic horseshoe SST anomaly on the early winter NAO seen in the observations (Czaja and Frankignoul 1999, 2002). As the horseshoe SST anomaly was shown by GDF to be correlated in phase with the AMO at low frequency in both IPSL CM5 and observations, and the AMO patterns are rather similar, the air-sea interactions in IPSL CM5 seemed broadly realistic, suggesting that an AMOC intensification tends to be followed by a negative NAO during winter. GF12 found a similar AMOC influence on the NAO during the cold season in five other climate models, but other models may behave differently.

The aim of this study is to determine whether AMOC variability in the (relatively) high-resolution T85 version of the Climate Community System Model, version 3 (CCSM3) (Collins et al. 2006), has a significant impact onto the large-scale atmospheric circulation and to evaluate the degree of realism of such air-sea interactions. After initial adjustment, the AMOC variability in a 700-yr control simulation showed two different regimes (see Fig. 1 in Danabasoglu 2008). The AMOC was in a quasi-oscillatory regime for $300 \mathrm{yr}$ with a 20 -yr dominant period, as investigated by Danabasoglu (2008) and Tulloch and Marshall (2012). The regime then changed abruptly, showing weaker and slower red noise-like fluctuations in the last $250 \mathrm{yr}$, as analyzed by Kwon and Frankignoul (2012). Danabasoglu (2008) has suggested that the 20-yr cycle in the oscillatory regime may reflect an atmosphere-ocean coupled mode, while Kwon and Frankignoul (2012) argued that the AMOC variability in the red noise regime was dominated by a damped ocean mode driven by stochastic NAO forcing. Here, we show that in each regime the AMOC variability has a significant influence on the atmospheric circulation, albeit with different and perhaps opposite features. We also investigate whether the atmospheric response to the AMOC can be detected at the seasonal scale using SST or upper-ocean heat content anomalies. Finally, we discuss how the oceanic influence in CCSM3 compares with the observations.

\section{Model}

The National Center for Atmospheric Research (NCAR) CCSM3 with T85 atmospheric resolution coupled to a $1^{\circ}$ ocean model (T85x1) is described in Collins et al. (2006). The atmospheric component is the Community Atmosphere Model, version 3 (CAM3), with 26 vertical levels and T85 horizontal resolution (approximately $1.4^{\circ}$ resolution). The ocean component is the Parallel Ocean Program, version 1.4 (POP1.4), with a zonal resolution of $1.125^{\circ}$ and a meridional resolution of $0.27^{\circ}$ at the equator gradually increasing to a maximum of approximately $0.6^{\circ}$ at about $40^{\circ} \mathrm{N}$. There are 40 levels in the vertical, whose thickness monotonically increases from $10 \mathrm{~m}$ near the surface to $250 \mathrm{~m}$ below $1500 \mathrm{~m}$. The other components, the Community Land Model, version 3 (CLM3), and the Community Sea Ice Model, version 5 (CSIM5), have the same horizontal resolution as the atmospheric and ocean components, respectively. The control integration uses greenhouse gases concentrations set to their 1990 levels. The ocean model was initialized from rest with the January mean climatological temperature and salinity from Levitus et al. (1998) and, for the Arctic Ocean, Steele et al. (2001). The other components were initialized with January conditions obtained from stand-alone integrations. The control integration was run for $700 \mathrm{yr}$ without any flux adjustment, as documented in Collins et al. (2006). After an initial adjustment of $50 \mathrm{yr}$, the strength of the AMOC very slowly decreased during the first part of the integration, stabilizing at about $22 \mathrm{~Sv}\left(1 \mathrm{~Sv} \equiv 10^{6} \mathrm{~m}^{3} \mathrm{~s}^{-1}\right)$. The AMOC was first in an oscillatory regime with a dominant period of about $20 \mathrm{yr}$ and an amplitude of $4 \mathrm{~Sv}$ (years 150-449), which was investigated by Danabasoglu (2008). The regime then changed abruptly, showing weaker and red noise-like fluctuations of about $2 \mathrm{~Sv}$ in the last $250 \mathrm{yr}$ (years 450-699), with a dominant time scale (period) of 30-40 yr, which was investigated by Kwon and Frankignoul (2012).

The atmospheric circulation is largely realistic and the storm track fairly well represented in CCSM3, but there are biases in the position of the NAO and other North Atlantic regimes as the mean Icelandic low is stronger and displaced southeastward relative to observations (Alexander et al. 2006), which is a common bias found in other coupled models. The mean oceanic fields are broadly realistic but exhibit some significant biases in the North Atlantic that are also commonly found in global climate models of similar resolution. Although the separation of the Gulf Stream (GS) is well located, 
the path of the Gulf Stream/North Atlantic Current (GS/NAC) is too zonal near the tail of the Grand Banks, resulting in a large cold and fresh bias near the surface around $40^{\circ}-50^{\circ} \mathrm{N}, 50^{\circ}-20^{\circ} \mathrm{W}$ (Large and Danabasoglu 2006; Danabasoglu 2008). The main deep convection site in the North Atlantic is centered in the western subpolar gyre near $54^{\circ} \mathrm{N}, 45^{\circ} \mathrm{W}$. It extends too much to the southeast and not enough into the Labrador Sea. Secondary convection sites are located southwest of Iceland in the Irminger Current and in the northwestern Nordic Seas, but the deep overflow water is poorly represented. There are small differences between the climatology of the two regimes, presumably reflecting the long spinup time of the deep circulation. In particular, in the red noise regime the westerlies are somewhat weaker, the subpolar gyre is slightly weakened and extended eastward, and the strength of the deep western boundary current (DWBC) and of the lower branch of the AMOC are reduced; the GS/NAC is also shifted south, resulting in a strong cooling along the GS/NAC (Fig. 1). We will suggest elsewhere that the slow drift in the model climatology explains the change from an oscillatory to a red noise AMOC regime (Y.-O. Kwon and C. Frankignoul 2013, unpublished manuscript).

\section{Statistical method}

To remove possible model drift, a second-order trend was removed from all variables prior to analysis. The main patterns of covariability between the ocean and the atmosphere are investigated with a lagged maximum covariance analysis (MCA) (von Storch and Zwiers 1999). The MCA isolates pairs of spatial patterns and their associated time series by performing a singular value decomposition of the covariance matrix between two fields. Each field is expanded into orthogonal patterns that maximize their area-weighted covariance, the time series being orthogonal to one another between the two fields. Each MCA mode is characterized by its squared covariance (SC), the correlation $R$ between the two time series, and the SC fraction (SCF) that it represents. Because of the stochastic character of the intrinsic atmospheric variability, the lagged MCA has been extensively used to detect oceanic influence on the atmosphere since the relationships between oceanic and atmospheric fields are indicative of the influence of the ocean on the atmosphere when the ocean leads by more than the atmospheric persistence (Frankignoul et al. 1998). However, other boundary forcing such as sea ice (e.g., Alexander et al. 2004) or continental snow cover (Cohen et al. 2007) may also play a role. To establish whether the MCA modes are meaningful, statistical significance was estimated using a moving blocks bootstrap approach as in Czaja and Frankignoul (2002): each MCA was repeated 100 times, linking the original oceanic anomalies with randomly scrambled atmospheric ones based on blocks of two successive years to reduce the influence of possible serial correlation in the atmosphere. The quoted significance levels indicate the percentage of randomized SC and $R$ for the corresponding mode that exceeds the value being tested. It is an estimate of the risk of rejecting the null hypothesis (there is no correlation between atmospheric and oceanic anomalies) when it is true. A smaller significance level indicates stronger evidence against the null hypothesis. The MCA isolates pair of spatial patterns, but the singular vectors associated with the two fields are not linearly related. As in Czaja and Frankignoul (2002), we show as covariance maps the homogeneous oceanic patterns and heterogeneous atmospheric patterns, which are obtained by regression onto the normalized oceanic time series, since they represent typical amplitude, preserve linear relation, and are the most appropriate to describe the atmospheric response to ocean changes.

Since ENSO significantly affects the atmospheric circulation in the North Atlantic sector and introduces a persistent component in the atmospheric fields, it could bias the estimated response to the AMOC or to extratropical SST forcing. As shown by Frankignoul and Kestenare (2002), the bias can largely be avoided if the ENSO teleconnections are first removed from both the oceanic and atmospheric variables. This was done seasonally at each grid point by using 3-month running periods and linear regression on the first two principal components of SST anomalies in the equatorial Pacific $\left(12.5^{\circ} \mathrm{S}-12.5^{\circ} \mathrm{N}, 100^{\circ} \mathrm{E}-80^{\circ} \mathrm{W}\right)$. The asymmetry in the response to ENSO (Alexander et al. 2006) and its delay (small at the seasonal scale) are neglected, so that the ENSO signal may not be entirely removed.

The MCA was first used to determine if the AMOC fluctuations influence the large-scale atmospheric circulation in CCSM3. To take into account the seasonal variability of the atmospheric circulation but highlight the low frequencies, we use yearly values of the AMOC streamfunction between $30^{\circ} \mathrm{S}$ and $80^{\circ} \mathrm{N}$ and 3-month averages of sea level pressure (SLP) anomalies in the North Atlantic sector $\left(10^{\circ}-80^{\circ} \mathrm{N}, 100^{\circ} \mathrm{W}-20^{\circ} \mathrm{E}\right)$. Hence, for each year SLP is taken in January-March (JFM), February-April (FMA), March-May (MAM), etc. (where each month is described by its first letter). The lag is given in year, but the effective lag slightly varies with the season selected for SLP. Prior to each MCA, we apply a small temporal smoothing $(1 / 4-1 / 2-1 / 4$ filter $)$ to the yearly seasonal SLP and yearly AMOC time series that decreases the noise without affecting seasonality. As the behavior of the AMOC differs in the oscillatory regime 

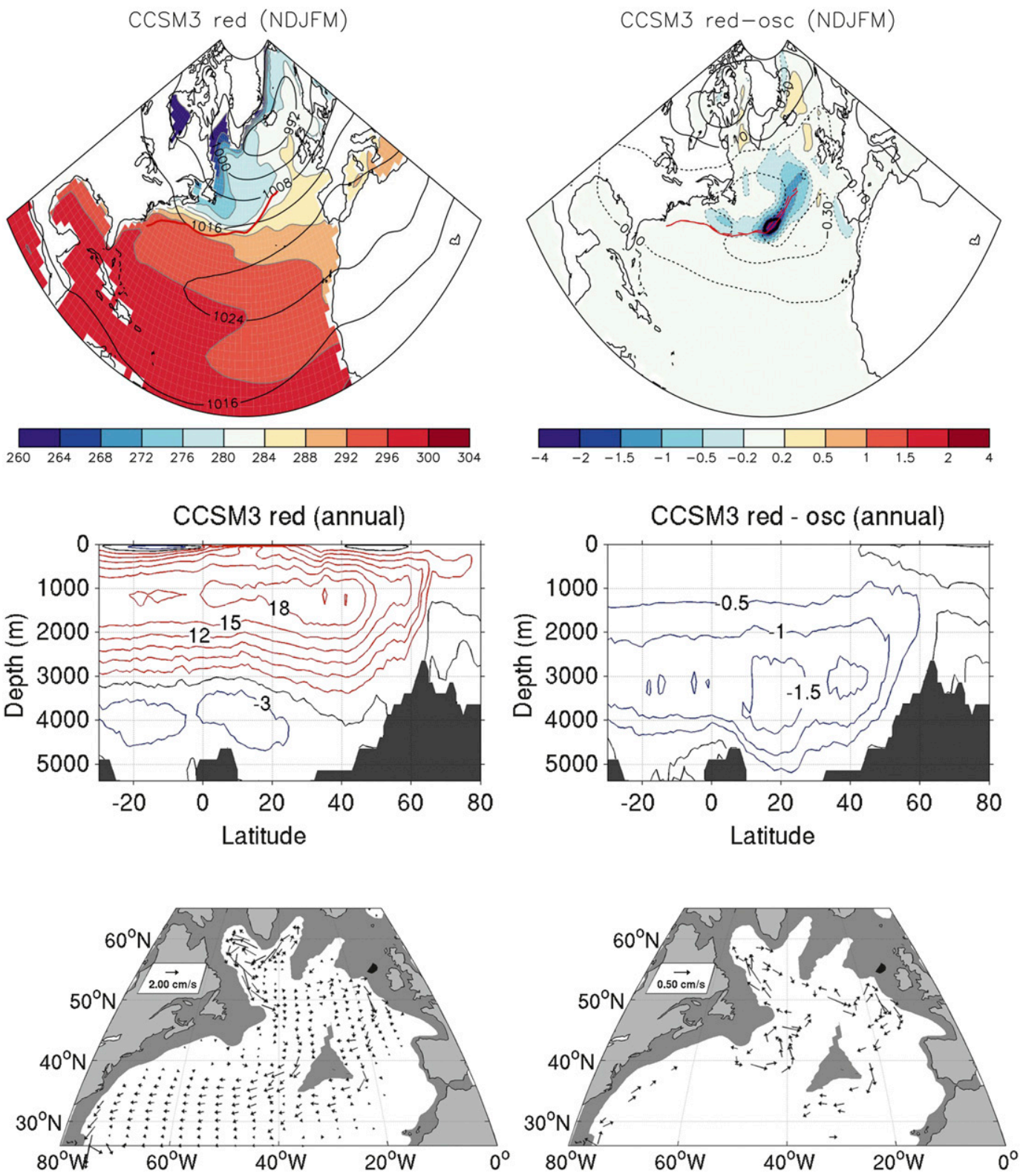

FIG. 1. (left) Climatological mean in the red noise regime and (right) mean difference with the oscillatory regime of (top) SST (K; color shading) and sea level pressure in the cold season from November to March (hPa; contours, zero line omitted), (middle) AMOC (Sv), and (bottom) 2000-3000-m velocity ( $\mathrm{cm} \mathrm{s}^{-1}$ ). Note that only the vectors greater than $0.2 \mathrm{~cm} \mathrm{~s}^{-1}$ are plotted for the mean difference of 2000-3000-m velocity. In the top panels, the red continuous (dashed) line indicates the Gulf Stream position for the red noise (oscillatory) regime.

(years 150-449) and the red noise regime (years 450 699), the two regimes are considered separately. In both regimes, however, the strongest covariability between SLP and the AMOC occurs when the AMOC lags or is simultaneous with the fall and winter SLP (Fig. 2), reflecting the forcing of the AMOC by the NAO in the cold season, as illustrated for the red noise regime in Fig. 3 (top). In the oscillatory regime, the covariability between the AMOC and SLP is stronger, reflecting the stronger AMOC variability during that period, but the MCA patterns are nearly undistinguishable (not shown). As the AMOC response has been extensively discussed in Danabasoglu (2008) and Kwon and Frankignoul (2012), we focus on the relation between SLP and prior AMOC variations (lag $>0$ ), which likely reflects an oceanic influence on the large-scale atmospheric circulation. Because of the temporal smoothing, results at neighboring lags are not independent, but the strong simultaneous 

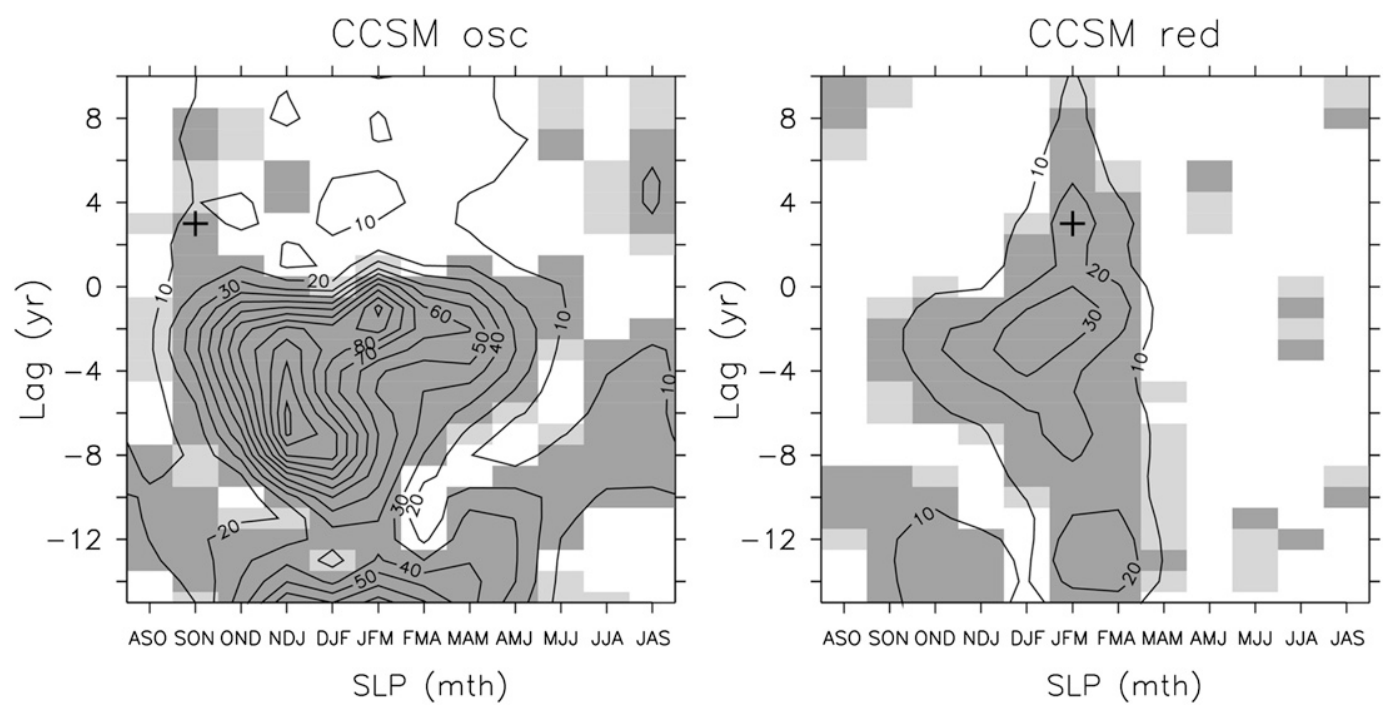

FIG. 2. SC $\left(10^{4} \mathrm{hPa}^{2} \mathrm{~Sv}^{2}\right)$ of the first MCA mode between SLP and the AMOC in the (left) oscillatory and (right) red noise regimes. The light (dark) gray shade indicates SC significance at the $10 \%(5 \%)$ level. The lag is positive when the AMOC leads and negative when it lags. (A cross indicates the lag for which the patterns will be illustrated in Figs. 3 and 10.)

relation between SLP and the AMOC, which reflects the AMOC response to the atmosphere, only weakly biases the results when the AMOC leads by 2 yr (lag 2$)$, and the results only reflect the oceanic influence when the AMOC leads by $3 \mathrm{yr}$ or more (lag $\geq 3 \mathrm{yr}$ ).

We also use a MCA between seasonal SLP and SST anomalies to see whether the AMOC imprint on the atmosphere could be detected in surface data. It furthermore allows the comparison of model and observations, thus assessing the realism of the air-sea interactions in CCSM3, as was done for IPSL CM5 by GDF. To enhance the signal-to-noise ratio, we have also considered seasonal anomalies of the average temperature in the upper $200 \mathrm{~m} T_{0-200 \mathrm{~m}}$ that are proportional to the heat content of the upper $200 \mathrm{~m}$. They are more persistent than SST anomalies and less strongly affected by weather fluctuations, thereby more likely to reflect the AMOC influence. In each regime, the seasonal air-sea interactions were investigated as a function of time of year by a MCA between 3-month running averages of SST or $T_{0-200 \mathrm{~m}}$ anomalies in the domain $10^{\circ}-80^{\circ} \mathrm{N}$, $100^{\circ} \mathrm{W}-20^{\circ} \mathrm{E}$ and SLP anomalies over the same domain. The regions where the climatological sea ice coverage exceeds $50 \%$ are excluded from the analysis, but the results are not sensitive to the precise limits of the domain and the sea ice threshold. When SLP leads either SST or $T_{0-200 m}$ (or when they are simultaneous), the MCA modes primarily reflect the upper-ocean response to the main modes of atmospheric variability, as in the observations. These air-sea interactions have been discussed by Alexander et al. (2006), who noted that the main SST anomaly patterns are not very realistic in the North Atlantic as their centers are overly concentrated near $45^{\circ} \mathrm{N}$ because of inaccurate representation of the GS and the subpolar gyre. We investigate below the relation between seasonal SLP and either SST or $T_{0-200 \mathrm{~m}}$ anomalies when the ocean leads SLP by at least 2 or 3 months, which has not been discussed previously and reflects the atmospheric response to the oceanic variability.

We first discuss the red noise regime since the AMOC might be closer to a statistically steady state (longer spinup), and the longer AMO time scale is more comparable to the approximate time scale of $70 \mathrm{yr}$ estimated from SST observations and reconstructions (Delworth and Mann 2000).

\section{Oceanic influence on the atmospheric circulation in the red noise regime}

\section{a. AMOC influence}

When the AMOC leads SLP, the first MCA mode is most significant and has the largest covariance for SLP in winter, with a peak in JFM (Fig. 2, right). The mode is robust and was also highly significant without temporal smoothing. A weaker and less robust AMOC influence is detected in April-June (AMJ) and, with temporal smoothing, in summer. In JFM, the first MCA mode is at least 5\% significant in both SC and $R$ until lag 8 , with maximum SC when SLP lags the AMOC by $3 \mathrm{yr}$, and it is seen at larger lag, reflecting its robustness and the persistence of the AMOC. The mode is well separated as its 

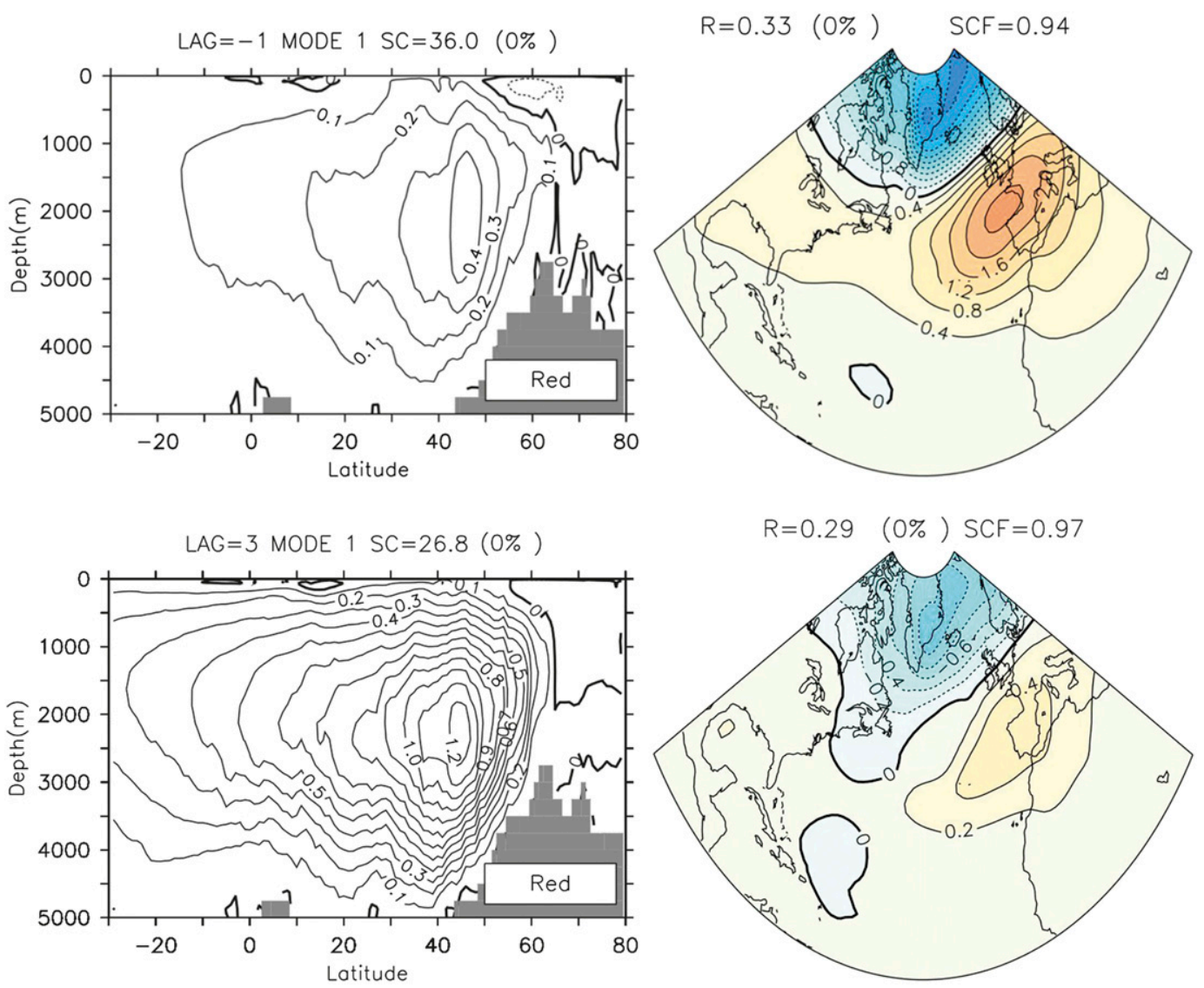

FIG. 3. (top) Heterogeneous map of the (left) yearly AMOC (Sv) and (right) homogeneous map of JFM SLP (hPa) for the first MCA mode in the red noise regime when SLP leads the AMOC by $1 \mathrm{yr}$. (bottom) Corresponding homogeneous map of the (left) yearly AMOC and (right) heterogeneous map of JFM SLP when SLP lags the AMOC by 3 yr. SC $\left(10^{4} \mathrm{hPa}^{2} \mathrm{~Sv}^{2}\right), R$, and their estimated significance level are indicated.

SCF exceeds $90 \%$ until lag 15 . As shown by the covariance maps in Fig. 3, an intensification of the AMOC tends to be followed in winter by a positive NAO-like pattern. The AMOC pattern is nearly identical to the first empirical orthogonal function (EOF1) of the meridional overturning streamfunction (cf. with Fig. 3 of Kwon and Frankignoul 2012), typically reaching $1.2 \mathrm{~Sv}$ near $45^{\circ} \mathrm{N}$. The SLP response resembles a positive NAO, except that the Icelandic low is $50 \%$ deeper than the Azores high compared to SLP EOF1, reaching about $1.1 \mathrm{hPa}$ north of Iceland for a $0.5-\mathrm{hPa}$ high off the Iberian Peninsula that corresponds to $20 \%-30 \%$ of the typical amplitude of the NAO in JFM (after $1 / 4-1 / 2-1 / 4$ smoothing). About $7.5 \%$ of the NAO JFM variance is explained by the atmospheric response. However, as the AMOC only varies slowly (10-yr $e$-folding time), the percentage of explained variance should be larger at low frequency. The signal is barotropic, without westward tilt with height (not shown). The correlation between the MCA time series exceeds 0.25 for SLP lagging by up to $5 \mathrm{yr}$, but the correlation might be biased high in a MCA since the covariance is maximized. The crossvalidated correlation obtained by removing successive sets of $3 \mathrm{yr}$ before performing the MCA and then using the MCA patterns to determine the amplitude of the midyear is lower at lag $3(R=0.18)$, but it reaches 0.28 at lag 6 . In addition, weak but significant correlations $(R \sim 0.2)$ are found independently by correlating the AMOC EOF1 time series (PC1) with the winter SLP PC1 lagging by several years. This suggests that the AMOC influence accounts for a small but significant fraction of the winter-to-winter NAO fluctuations in the model, in particular at high latitudes. Since the AMOC variability is largely driven by the natural variability of the NAO, a positive NAO driving a stronger AMOC (Fig. 3; see also Kwon and Frankignoul 2012), the atmospheric response to the AMOC acts as a weak positive feedback in the red noise regime.

The NAO-like response appears to be driven by the SST and the surface heat flux anomalies induced by the 


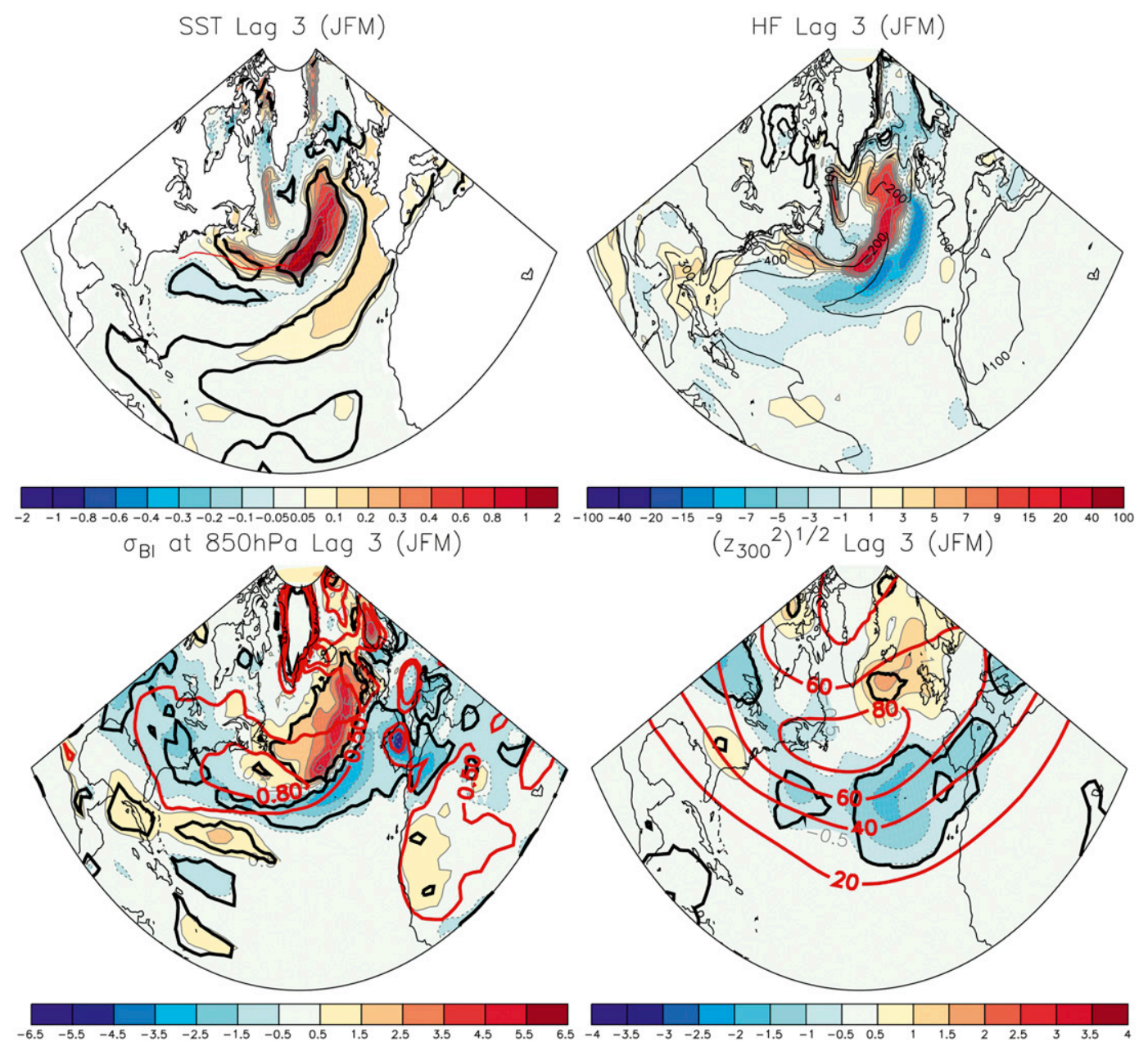

FIG. 4. Regression in the red noise regime of (top left) winter JFM SST (K; mean GS/NAC position in red), (top right) upward surface heat flux $\left(\mathrm{W} \mathrm{m}^{-2}\right.$; climatology in thin black contours), (bottom left) Eady growth rate $\left(10^{-2}\right.$ day $^{-1}$; climatology in red contours with contours at 0.5 and 0.8 day $\left.^{-1}\right)$, and (bottom right) 300-hPa geopotential height daily bandpass (2.2-6 days) standard deviation ( $\mathrm{m}$; climatology in red contours) onto the AMOC time series obtained at lag 3, lagging it by $3 \mathrm{yr}$. The thick black contours (omitted for clarity in the top right panel) indicate $5 \%$ significance.

AMOC changes. Figure 4 shows the lag regression of a number of fields in JFM (after a $1 / 4-1 / 2-1 / 4$ smoothing) onto the AMOC time series from the leading MCA mode between the AMOC and SLP lagging by $3 \mathrm{yr}$ (as shown in Fig. 3). The spatial anomalies lag the AMOC time series by $3 \mathrm{yr}$, so they correspond to the winter SLP response in the MCA shown in Fig. 3 (similar patterns would be obtained by regressing on AMOC PC1 with a 3-yr lag). In the red noise regime, an AMOC intensification is accompanied by a northward shift of both the GS and the NAC. This causes a strong SST increase along the GS/NAC, extending well into the eastern subpolar gyre, together with a weaker cooling to the south and in the Norwegian Sea (Fig. 4, top left). The SST pattern changes little with lag, and the SST anomalies are very small in the North Pacific and the tropics (not shown). The surface heat flux anomaly (top right) has a similar pattern, reflecting that the surface heat flux damps ocean-driven SST anomalies, like in the observations (Frankignoul and Kestenare 2002). However, the reduction in oceanic heat loss south of the NAC is nearly as strong as its increase along the NAC, so that the anomalous heating resembles a crescentshape north-south dipole. This could occur because the heating associated with a SST front extends downwind in strong winds as the air temperature does not have time to adjust to SST changes, so that the heating is broader and frontal displacements lead to dipolar heating changes (e.g., Small et al. 2008). Upward heat flux warms the air over warm SST anomalies; hence, warmer air is 
advected over the negative SST anomaly located downstream, where it amplifies the downward heat flux. As shown by its location with respect to the climatology, the anomalous heating shifts northward and extends northeastward, the western subtropical region of maximum heat release to the atmosphere. This affects the baroclinicity of the lower troposphere and thus the synoptic perturbation growth. The maximum Eady growth rate defined by $0.31 f|\partial u / \partial z| N^{-1}$, where $f$ is the Coriolis parameter, $\partial u / \partial z$ is the zonal wind shear, and $N$ is the Brunt-Väisälä frequency, governs the amplitude of the atmospheric perturbations (Hoskins and Valdes 1990). Its climatology (Fig. 4, bottom left, in red) shows that the region of maximum growth rate at $850 \mathrm{hPa}$ is located over the GS region from Cape Hatteras to the Grand Banks of Newfoundland that corresponds to the location of the largest upward surface heat flux over the North Atlantic. The anomalous maximum Eady growth rate shifts the maximum growth rate northward, and extends its tail end northeastward. This decreases the storm track over the subtropics, while shifting and extending it northeastward, as shown by the standard deviation of the bandpass-filtered (2.2-6 days) 300-hPa geopotential height calculated from daily outputs (Fig. 4 , bottom right), consistent with the positive NAO response in Fig. 3. Note that the variability of the North Atlantic storm track is biased in CCSM3, as the meridional shifts of the storm-track exit are a more prevalent mode of variability than storm-track strengthening, opposite to the observations (Alexander et al. 2006).

In summary, during winter the AMOC variability modulates the North Atlantic SST and the heat released to the atmosphere, shifting meridionally the lower-level baroclinicity and the maximum growth of the transient eddies. This affects the storm track and leads to a NAOlike response. The latter has significant climate impacts, with $850-\mathrm{hPa}$ temperature anomalies coarsely resembling the anomalies observed during a positive NAO phase (warming in western Europe and much of North America and cooling over Greenland), together with an increase in precipitation over Ireland, Scotland, and Norway and a decrease in a few regions in North America. The AMOC variability also affects sea ice concentration, as the ice edge retreats when SST is warmer and expands when SST is colder. Although the sea ice concentration changes and the associated heat fluxes were small (not shown), it is not excluded that they contribute to the atmospheric response.

\section{b. Air-sea interactions at the seasonal scale}

Since it does not take more than a month or two for the atmosphere to respond to anomalous boundary forcing (Ferreira and Frankignoul 2005; Deser et al. 2007),

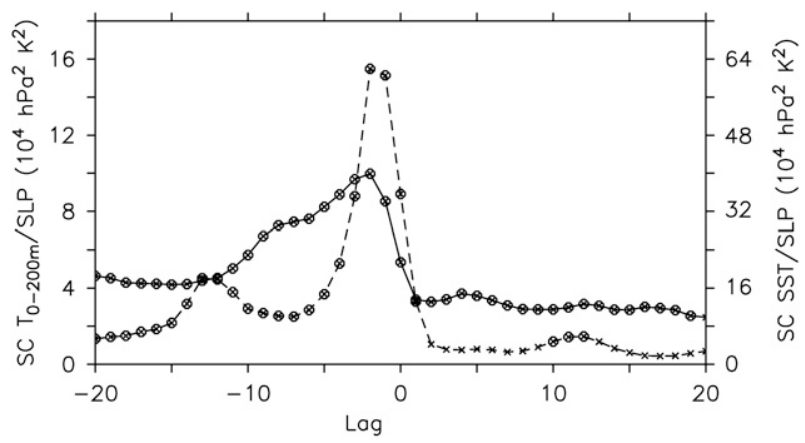

FIG. 5. SC $\left(10^{4} \mathrm{hPa}^{2} \mathrm{~K}^{2}\right)$ of the first MCA mode as a function of time lag (month; positive when SLP lags) for SLP anomalies in FMA and $T_{0-200 \mathrm{~m}}$ (solid curve) or SST (dashed curve) anomalies in the red noise regime. Full circles indicate 5\% significance.

and the response strongly depends on the season (Czaja and Frankignoul 2002), the slowly varying SST changes caused by the AMOC variability could only influence the atmosphere via their repeated seasonal impact in successive years. Hence, if the AMOC influence is sufficiently strong, this seasonal impact should be detectable at the seasonal scale in the relation between SST and the atmosphere. However, local atmospheric forcing may generate SST anomalies similar to the AMOC footprint, albeit less persistent, which similarly influence the atmosphere. Hence, as discussed in GDF, signals detected at the seasonal scale could be attributed to an AMOC influence if their persistence matches that of the AMOC or the AMO. In any case, the seasonal analysis may be used to test the realism of the model air-sea interactions by comparing them with the observations.

An MCA was thus performed between seasonal SLP and SST or $T_{0-200 \mathrm{~m}}$ anomalies, independently from the MCA with the annual-mean AMOC, without applying any low-pass filtered prior analysis. As illustrated in Fig. 5, the main covariability occurs when SLP leads or is in phase, primarily reflecting the oceanic response to the weather variability. When the ocean leads, the first MCA mode is only significant in winter. In the MCA based on SST, statistical significance is limited and the mode is $5 \%$ significant only when SST leads SLP in FMA by 1, 10, 11, and 12 months (Fig. 5, dashed line). However, the MCA mode is very robust in FMA when using $T_{0-200 \mathrm{~m}}$ that is less affected by weather noise than SST. The SC is at maximum when SLP lags $T_{0-200 \mathrm{~m}}$ by 3 or 4 months, and it remains $5 \%$ significant at lag up to at least 19 months, consistent with the strong persistence of the $T_{0-200 \mathrm{~m}}$ mode (Fig. 5, continuous curve). As the covariance maps are very similar in the two cases, we show the more robust results based on $T_{0-200 \mathrm{~m}}$ (Fig. 6). The MCA patterns change little with lag, showing that a $T_{0-200 \mathrm{~m}}$ or SST anomaly resembling the AMOC-driven 

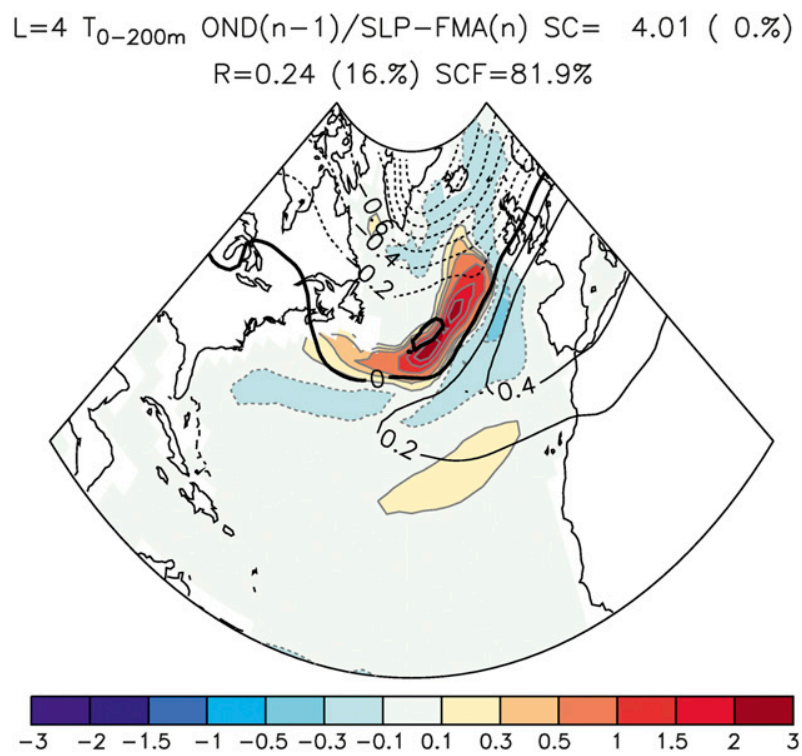

FIG. 6. Homogeneous covariance map of $T_{0-200 \mathrm{~m}}(\mathrm{~K}$; color shading) in OND and heterogeneous covariance map of SLP (hPa; contour interval $0.2 \mathrm{hPa}$ ) in FMA, 4 months later, for the first MCA mode in the red noise regime. SC $\left(10^{4} \mathrm{hPa}^{2} \mathrm{~K}^{2}\right)$ and $R$ are given with estimated significance level.

SST anomaly in Fig. 4, with a strong warming along the GS/NAC and a slight cooling south of it, precedes a positive phase of the NAO in winter, again with a deeper Icelandic low as in Fig. 3. Although the seasonal mode is most significant 1 month later than in the MCA with the yearly AMOC (SLP in FMA instead of JFM), it is also seen in the MCA between SLP in JFM and $T_{0-200 \mathrm{~m}}$, albeit less robustly. Since it has a striking resemblance to the AMOC imprint on the winter atmosphere, it confirms the robustness of the analysis and shows that the AMOC influence can be detected using upper-ocean temperature data. This is of interest for climate predictability, since the upper-ocean heat content seems to be more predictable than the AMOC (Teng et al. 2011).

\section{Oceanic influence on the atmospheric circulation in the oscillatory regime}

When the AMOC leads SLP, there is a significant MCA mode in summer and fall, but not in winter (Fig. 2). Why no AMOC influence is detected in winter seems to be due to the different SST fingerprint of the AMOC. Indeed, an intensification of the AMOC in the oscillatory regime is accompanied by a southward shift of the GS and a cooling in the GS region south of Newfoundland, opposite to the northward shift in the red noise regime. On the other hand, the NAC shifts northward farther east, leading to a warming along it that is similar to the AMOC footprint in the red noise regime, but for a larger penetration of the SST anomalies into the subpolar gyre. This is illustrated in Fig. 7 (left) by the regression of the surface heat flux in JFM, lagged by $3 \mathrm{yr}$, onto the AMOC EOF1 time series that corresponds to Fig. 4 for the red noise regime. Reflecting the SST modulation by the AMOC (which resembles the heat flux anomaly), the maximum heat release to the atmosphere in the oscillatory regime is mostly reduced and shifted southward west of $50^{\circ} \mathrm{W}$ but increased and extended northeastward farther east. The AMOC fingerprint on the maximum Eady growth rate is similar, as
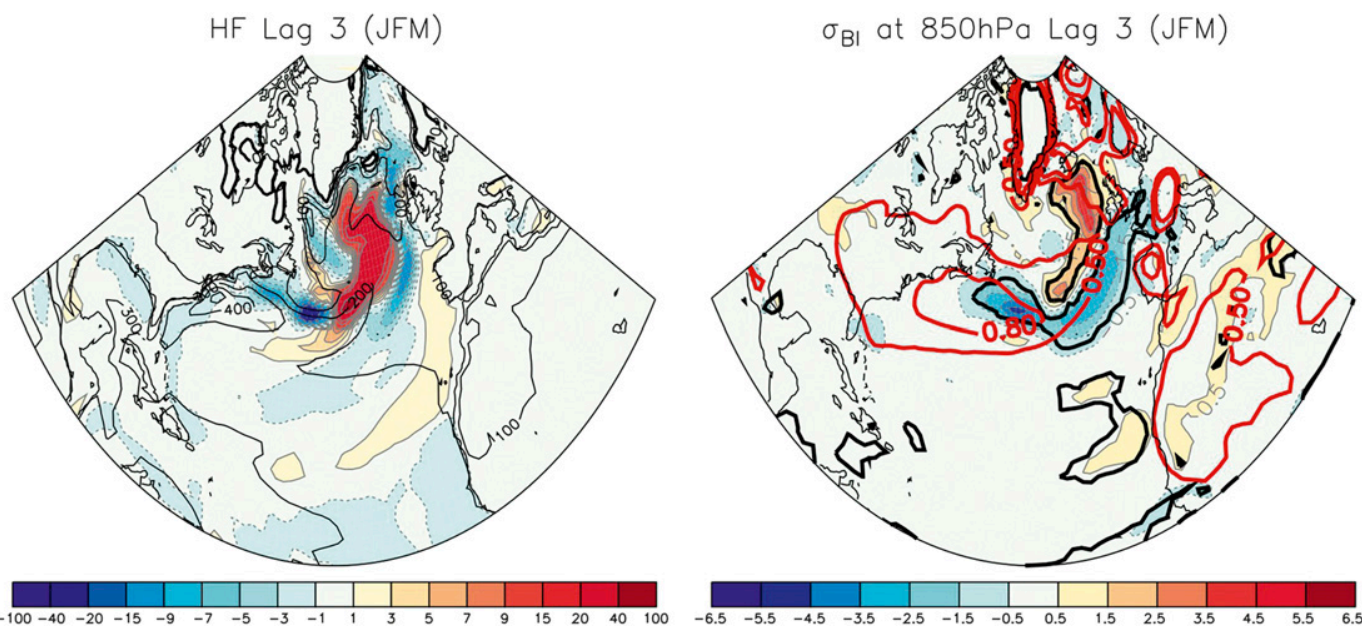

FIG. 7. Regression of the JFM (left) upward surface heat flux $\left(\mathrm{W} \mathrm{m}^{-2}\right.$; climatology in thin black contours) and (right) Eady growth rate $\left(10^{-2} \mathrm{day}^{-1}\right.$; contour interval $0.510^{-2} \mathrm{day}^{-1}$ and climatology in red with contours at 0.5 and $0.8 \mathrm{day}^{-1}$ ) onto the AMOC PC1 3 yr earlier in the oscillatory regime. The thick black contour in the right panel indicates $5 \%$ significance. 
the baroclinic growth is reduced and shifted south in the west (instead of north in the red noise regime) but increased and shifted north in the east (Fig. 7, right). The conflicting influence on the maximum growth rate suggests a weaker AMOC impact on the atmospheric circulation than in the red noise regime, where the Eady growth rate shift is northward everywhere, perhaps explaining the absence of significant winter MCA modes. Nonetheless, indirect evidence of a winter response to the AMOC is found in the seasonal analysis based on the upper-ocean heat content. Indeed, a significant oceanic influence on the atmosphere in JFM-MAM is detected in the MCA between $T_{0-200 \mathrm{~m}}$ and SLP, with maximum significance in FMA. The SC of the first MCA mode has two maxima when SLP lags by 4 and 15 months, and it is mostly $5 \%$ significant when SLP in FMA lags $T_{0-200 \mathrm{~m}}$ by at least 20 months. The mode patterns that change very little with lag are shown in Fig. 8 (top). A strong increase in the upper-ocean heat content along the NAC and a strong decrease south of Newfoundland, plus a weaker one south of the NAC, precedes a SLP pattern broadly resembling a negative phase of the NAO by several months. Note that the heat content anomaly near the Gulf Stream, where the synoptic perturbations have their maximum growth, is opposite to that in the red noise regime (cf. with Fig. 6) and that the SLP high and the low have similar amplitude, unlike in the red noise regime where the Icelandic low was stronger (see Figs. 3 and 6). Interestingly, the $T_{0-200 \mathrm{~m}}$ anomaly resembles that obtained by regression onto AMOC PC1 when AMOC and $T_{0-200 \mathrm{~m}}$ are simultaneous (Fig. 8, middle). However, as the lag with the AMOC increases, the similarity in $T_{0-200 \mathrm{~m}}$ patterns decreases because the warming spreads cyclonically in the subpolar gyre, as shown for lag 3 (Fig. 8, bottom) where the $T_{0-200 m}$ pattern resembles the heat flux pattern in Fig. 7, consistent with a negative heat flux feedback. That the atmosphere seems most sensitive to the heat content pattern that varies in phase with an AMOC intensification may also explain why no significant AMOC influence was detected in the MCA in Fig. 2, since the simultaneous covariability between the AMOC and SLP is dominated by the atmosphere forcing of the AMOC, thus masking a possible back interaction. If the $T_{0-200 \mathrm{~m}}$ mode in Fig. 8 was indeed an AMOC footprint, then an AMOC intensification would generate a negative NAO, opposite to the positive NAO seen in the red noise regime. It would act as a negative feedback, perhaps contributing to the shorter AMOC time scale in the oscillatory regime. However, a somewhat different winter SLP response is detected in the seasonal MCA with SST, albeit lacking robustness, as it is only significant at large lag. For instance, it is $5 \%$ significant when SST leads SLP in

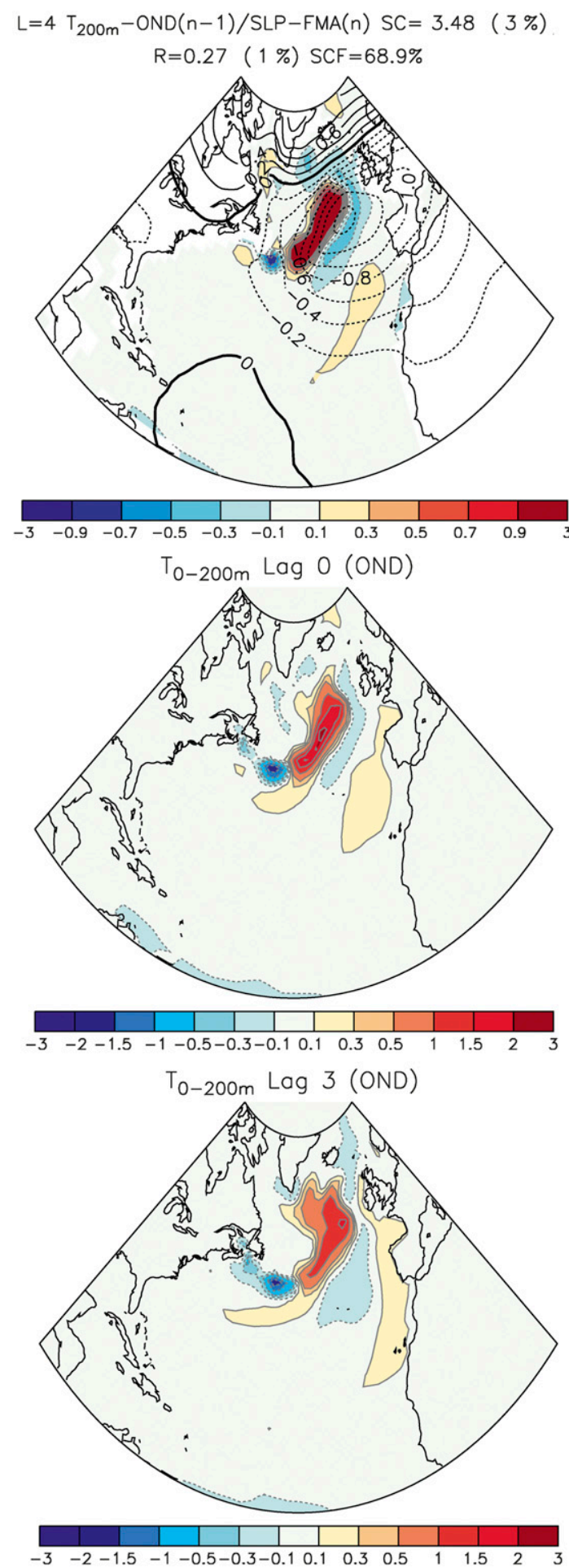

FIG. 8. (top) Homogeneous covariance map of $T_{0-200 \mathrm{~m}}(\mathrm{~K}$; color shading) in OND and heterogeneous covariance map of SLP (hPa; contours) in FMA, 4 months later, for the first MCA mode in the oscillatory regime. SC $\left(10^{4} \mathrm{hPa}^{2} \mathrm{~K}^{2}\right)$ and $R$ are given with the estimated significance level. (middle) Regression of $T_{0-200 \mathrm{~m}}(\mathrm{~K})$ in OND on AMOC PC1 in the oscillatory regime in phase and (bottom) lagged by 3 yr. 


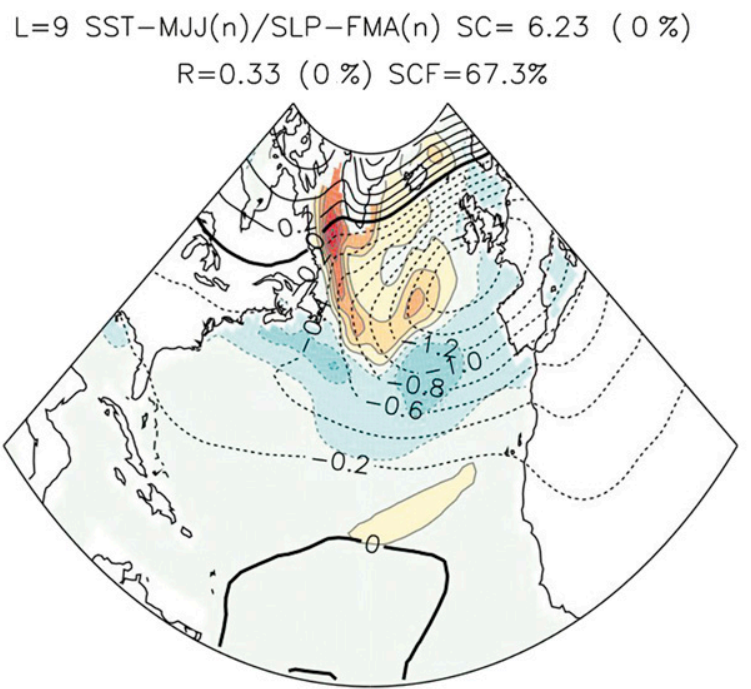

\begin{tabular}{|l|l|l|l|l|l|l|l|l|l|l|l|l|l|l|l|}
\hline & & & & & & & & & & & & & & & \\
\hline
\end{tabular}

FIG. 9. Homogeneous covariance map of SST (K; color shading) in MJJ and heterogeneous covariance map of SLP $(\mathrm{hPa}$; contour interval $0.2 \mathrm{hPa}$ ) in FMA, 9 months later, for the first MCA mode in the oscillatory regime. SC $\left(10^{4} \mathrm{hPa}^{2} \mathrm{~K}^{2}\right)$ and $R$ are given with the estimated significance level.

FMA by $9-16$ months. As illustrated in Fig. 9, the mode has limited resemblance with the $T_{0-200 \mathrm{~m}}$ mode in Fig. 8 , as the SLP pattern is shifted northward and the SST anomaly includes a strong warming in the Labrador Sea and a broader subtropical cooling. Hence, the SST pattern has only limited resemblance with the AMOC footprint. Altogether, the results suggest that the AMOC influence on the wintertime atmosphere is not as robust as in the red noise regime.

On the other hand, the MCA between the AMOC and SLP indicates that in the oscillatory regime the AMOC influences the atmospheric circulation in summer and fall (Fig. 2). The strongest signal is found when SLP is in September-November (SON), as the first MCA mode is mostly $5 \%$ significant for lag up to $8 \mathrm{yr}$. It shows that an intensification of the AMOC, also highly similar to AMOC EOF1, precedes a low centered above Iceland and typically reaching $0.6 \mathrm{hPa}$ (Fig. 10). The SLP response is nearly in spatial quadrature to the model NAO. It broadly resembles the second SLP EOF in SON (in both regimes), and it has some (limited) similarity with the east Atlantic pattern or the Scandinavian blocking. It brings cold air directly over the main deep convection site in the model, which might precondition winter convection, perhaps further strengthening the AMOC, and warm air over western Europe, where there is a significant 850 -hPa warming exceeding $0.15 \mathrm{~K}$ over France, Germany, Sweden, and the British Isles. The atmospheric response is baroclinic and confined to the surface (not shown). The lagged regression of the surface heat flux, which resembles the SST footprint of the $\mathrm{AMOC}$, and the maximum Eady growth rate in SON on the AMOC MCA time series obtained at lag 3, lagging it by $3 \mathrm{yr}$, is given in Fig. 11. It again shows that an intensification of the AMOC is primarily followed in the oscillatory regime by a cooling and reduced oceanic heat release in the GS region and south of Newfoundland, and a warming and enhanced heat release along the NAC, which is extended more in the subpolar gyre than in the red noise regime. The heat flux pattern resembles that in Fig. 7, reflecting that the SST and heat flux footprint of the AMOC varies very little with the season. The heat released to the atmosphere is thus shifted south near the GS but north along the NAC. The maximum Eady growth rate anomaly reflects this pattern but is small in the west and only significant near the eastern
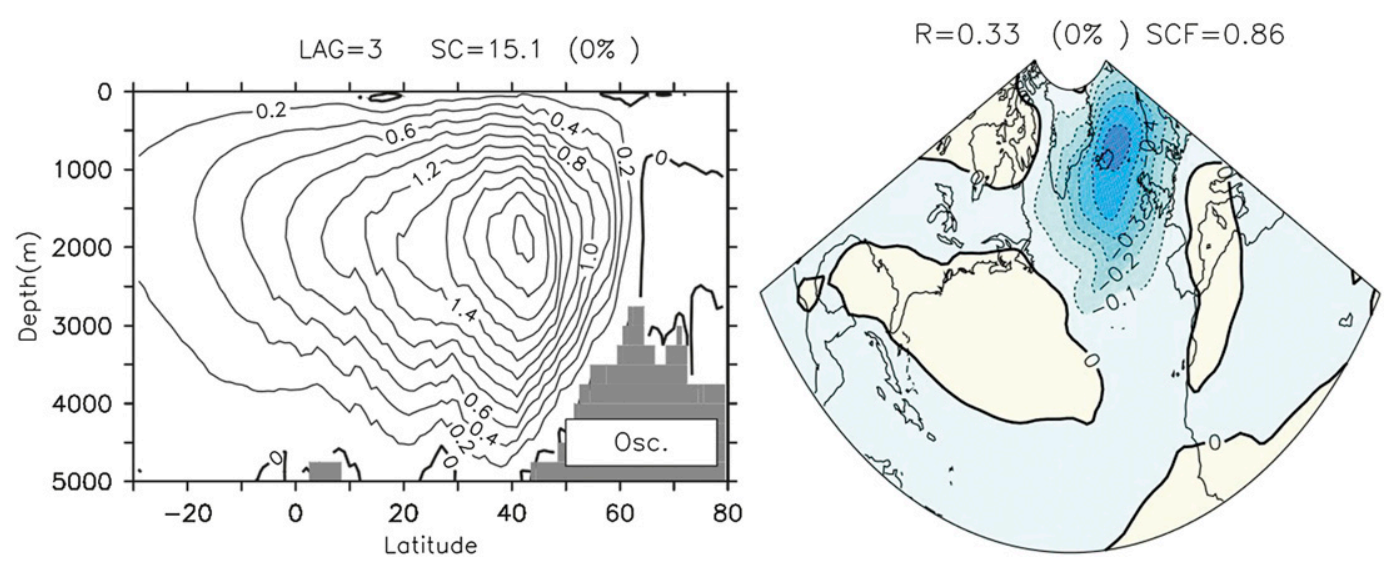

FIG. 10. (left) Homogeneous map of the yearly AMOC (Sv) and (right) heterogeneous map of SON SLP (hPa) for the first MCA mode in the oscillatory regime when SLP lags by $3 \mathrm{yr}$. SC $\left(10^{4} \mathrm{hPa}^{2} \mathrm{~Sv}^{2}\right), R$, and their estimated significance level are indicated. 

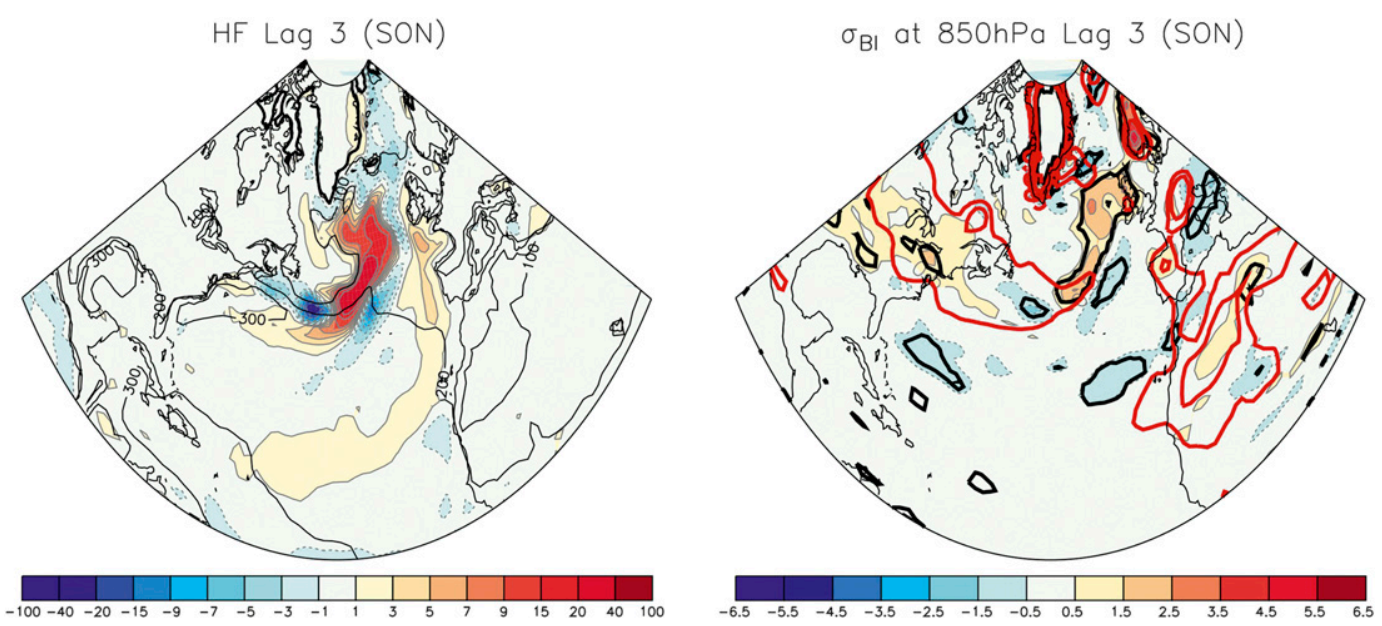

FIG. 11. Lagged regression of SON (left) upward surface heat flux ( $\mathrm{W} \mathrm{m}^{-2}$; climatology in thin black contours), (right) Eady growth rate $\left(10^{-2} \mathrm{day}^{-1}\right.$; contour interval $0.510^{-2} \mathrm{day}^{-1}$ and climatology in red with contours at 0.5 and $0.8 \mathrm{day}^{-1}$ ) onto the AMOC time series in the oscillatory regime. The thick black contours in the right panel indicate $5 \%$ significance.

edge of the region of maximum growth, extending it eastward. As a result, the storm track is shifted southward and the transient activity is reduced over the British Isles (not shown). However, no significant influence on SLP could be found during fall when using either SST or $T_{0-200 \mathrm{~m}}$ in the MCA analysis. It suggests a limited robustness of the AMOC influence during fall in the oscillatory regime.

We also investigated the lack of significant MCA mode during fall in the red noise regime. It was found that the SST modulation by the AMOC only significantly impacted the low-level baroclinicity downstream of the region of maximum growth, thus weakening but not shifting meridionally the maximum Eady growth rate and the storm-track activity (not shown). This suggests that the atmosphere in CCSM3 is most sensitive to meridional shifts in the baroclinicity of the jet exit region, which would be consistent with the prevalence of the meridional storm-track shifts over the exit region in this simulation, as noted by Alexander et al. (2006). In addition, the heat fluxes and the baroclinicity are weaker during fall, so it is expected that the AMOC influence will be weaker. We can also speculate that the limited robustness of the AMOC influence during fall occurs because in the model the maximum eddy growth occurs upstream over land and is thus less sensitive to the AMOC SST footprint. There is also some significant summer SLP response to the AMOC, with patterns similar to those in Fig. 10, except that the SLP low is displaced eastward and centered over Greenland, while there is a weaker high over Scandinavia (not shown). Hints of this response could be found using the MCA between SST and SLP.
Danabasoglu (2008) has argued that the SST footprint of the AMOC (Figs. 8 and 11) does not solely reflect an AMOC influence as the cooling/warming along the GS/NAC reflected opposing meridional shifts of the subtropical-subpolar gyre boundary driven by smallscale features in the local wind stress curl (the quadripolar wind stress curl pattern in his Fig. 6), thus being only indirectly associated with the AMOC. However, a closer examination reveals that this wind stress curl pattern reflects instead the wind vorticity response to the anomalous crosswind SST gradient caused by the meridional displacements of the GS/NAC front, as the westerlies along the NAC get stronger over the warm ocean because of enhanced vertical mixing and vice versa. This is shown by the regression on the latter in Fig. 12, where the wind stress curl is positive when SST decreases crosswind and negative when SST increases crosswind (Chelton et al. 2001; O'Neill et al. 2010). A similar signal is found in the red noise regime, except that the wind stress curl is positive near the Gulf Stream, consistent with its northward shift. Because of its small scale, this local atmospheric response is not detected in the MCA based on SLP in the North Atlantic sector.

\section{Comparison with the observations}

Extending the analysis of Czaja and Frankignoul (2002), GDF used the National Oceanic and Atmospheric Administration (NOAA)-Cooperative Institute for Research in Environmental Sciences (CIRES) Twentieth Century Reanalysis (Compo et al. 2011) during 19012005 to investigate the influence of North Atlantic SST anomalies on the observed atmospheric circulation. The 


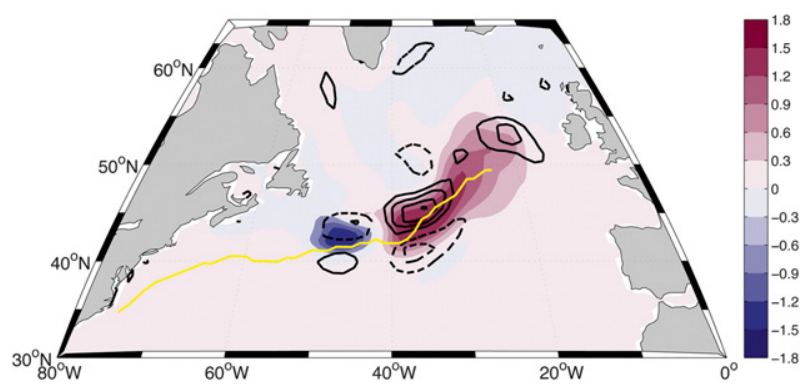

FIG. 12. Regression of SST (K; color shading) and wind stress curl (contour interval $10^{-8} \mathrm{~N} \mathrm{~m}^{-3}$, zero contour omitted) on the meridional position of the NAC at $30^{\circ} \mathrm{W}$ in the oscillatory regime. The mean position of the GS/NAC is given by the yellow curve.

Twentieth Century Reanalysis was forced with the Hadley Centre Sea Ice and SST dataset (HadISST) (Rayner et al. 2003) and only assimilates surface pressure reports. GDF used the ensemble-mean 500-hPa geopotential height anomalies (Z500) that are strongly linked to SLP because of the equivalent barotropic character of the main patterns of extratropical atmospheric variability. The warming trend because of increasing greenhouse gas concentrations during the twentieth century was removed from the SST by linear inverse modeling (Marini and Frankignoul 2013). Lacking a better model, a third-order trend was removed from the geopotential height. GDF found that the first MCA mode was only significant when SST leads the atmosphere in early winter, with maximum covariance when Z500 is in November-January (NDJ). The mode is robust, showing that a North Atlantic SST anomaly with a horseshoe pattern precedes an NAOlike signal (Fig. 13). It resembles that in Czaja and Frankignoul (2002), except that the warming in the subpolar region is stronger. This is because of the longer dataset and the strength of low-frequency fluctuations in the subpolar domain, which were largely filtered by removing a cubic trend in Czaja and Frankignoul (2002). The atmospheric response is likely to be a result of the interaction between the baroclinic response to the associated anomalous heating and the Atlantic storm track, but modeling studies have not been successful at reproducing it (e.g., Peng et al. 2005). GDF have shown that the observed North Atlantic horseshoe SST is closely related to the AMO, as it has a similar pattern (Fig. 14, bottom) and similar low-frequency variability.

In both regimes, however, the corresponding CCSM3 modes (Figs. 6, 8, and 9) compare poorly to the observed mode in Fig. 13. This occurs because the North Atlantic SST variability is largely dominated in CCSM3 by the strong meridional shifts of the GS/NAC, unlike in the observations. Correspondingly, the AMO pattern in

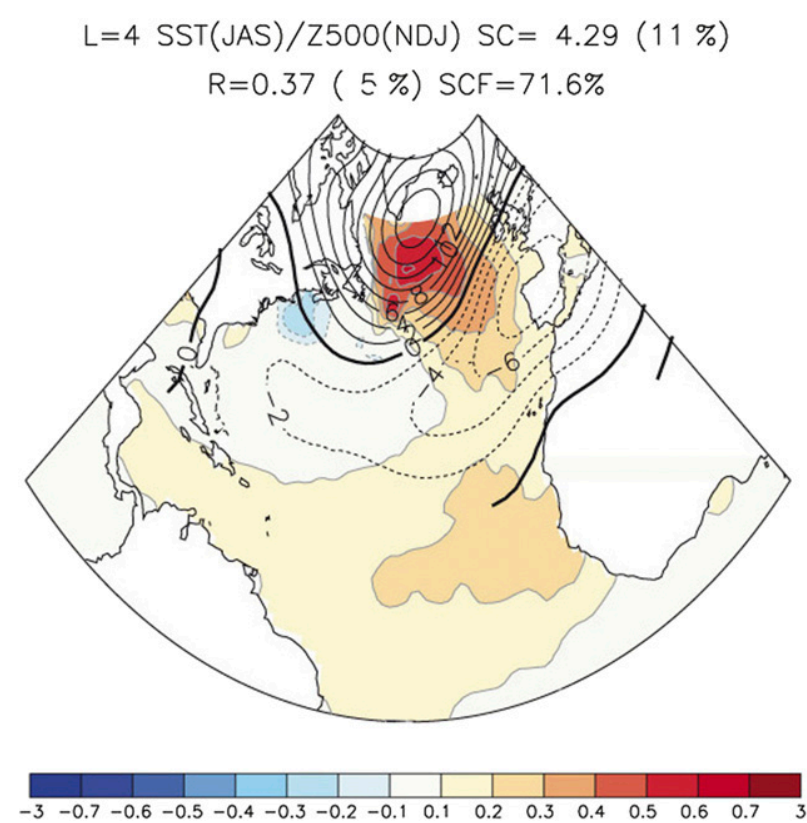

FIG. 13. Homogeneous covariance map of SST (K; color shading) in JAS and heterogeneous covariance map of Z500 (m; contours) in NDJ from the Twentieth Century Reanalysis. The lag (months) is indicated $(L=4)$. SC $\left(10^{6} \mathrm{~m}^{2} \mathrm{~K}^{2}\right)$ and $R$ are given with the estimated significance level. (Figure from GDF.)

CCSM3 is not realistic, as noted by Danabasoglu (2008) and illustrated in Fig. 14. Nonetheless, the mechanism of the wintertime atmospheric response in CCSM3 seems similar to that found in climate models producing a more realistic SST pattern, such as IPSL CM5, since in all cases the response appears to be consistent with AMOCdriven meridional shifts of oceanic heat release and baroclinicity in the jet exit region (GF12). However, the possible link to meridional GS shifts was not investigated in the other models.

\section{Conclusions}

In the T85 CCSM3, the influence of the AMOC variability on the large-scale atmospheric circulation, as detected by MCA between the meridional overturning streamfunction and SLP, varies with the AMOC regime. In the red noise regime seen in the last $250 \mathrm{yr}$ of the control simulation, an AMOC intensification, whose pattern closely resembles the first AMOC EOF, tends to lead a positive NAO during winter. The atmospheric response seems to arise from the northward shift of the maximum heat release to the atmosphere that is caused by the northward shift of the GS/NAC driven by or covarying with an AMOC intensification. This alters the baroclinicity of the lower troposphere and shifts the maximum Eady growth rate northward, which similarly 

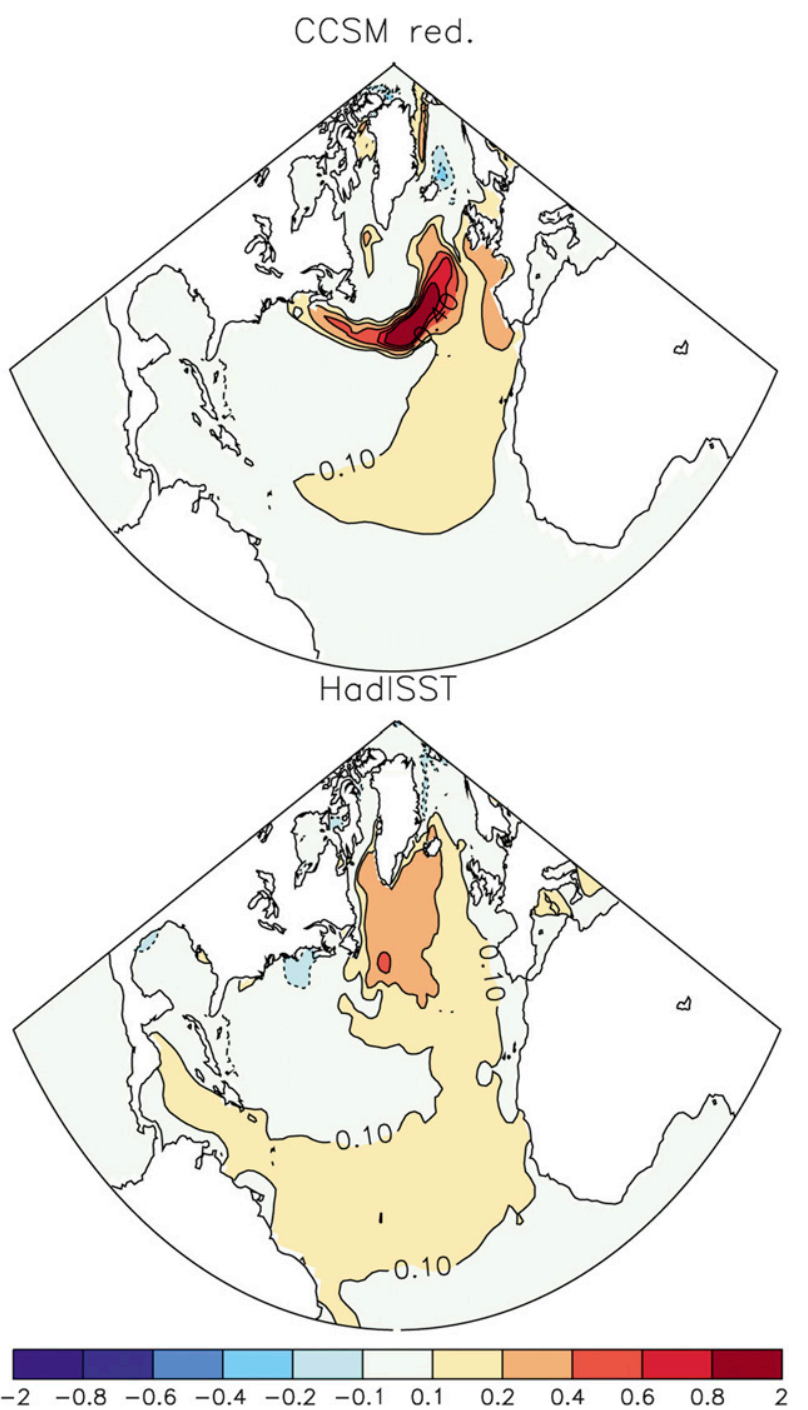

FIG. 14. (top) AMO (K) defined by the regression of the 10-yr low-pass filtered, mean Atlantic SST over $10^{\circ}-60^{\circ} \mathrm{N}$ onto the SST in the red noise regime of CCSM3 and (bottom) after subtraction of the global trend in HadISST.

displaces the North Atlantic storm track and favors a positive NAO. Although the signal-to-noise ratio is low, the mode is robust and it is detected at the seasonal scale detected in the relation between upper-ocean heat content anomalies and late winter SLP anomalies. However, the correlation between the AMOC and SLP time series associated with the first MCA is small (the maximum cross-validated correlation is 0.29 ). About $7.5 \%$ of the NAO JFM variance (after $1 / 4-1 / 2-1 / 4$ smoothing) is explained by the atmospheric response, so that only a small fraction of the winter-to-winter NAO fluctuations may be predictable, if the AMOC changes can be predicted. However, as the AMOC only varies slowly, the percentage of explained variance should be larger at low frequency. As the AMOC is largely stochastically forced by the NAO (Kwon and Frankignoul 2012) - a positive NAO leading to an intensified AMOC - the atmospheric response should act as a weak positive feedback, thereby enhancing the AMOC persistence.

In the oscillatory regime, the AMOC influence on the large-scale atmospheric circulation seems less robust, even if the AMOC variability is much stronger with large oscillations with a 20 -yr period. No direct AMOC influence on SLP could be detected by MCA, but an upper-ocean heat content anomaly that resembles the in-phase footprint of the AMOC was found by MCA to precede a negative NAO in winter. The polarity of the NAO response, opposite to that in the red noise regime, seems due to the southward shift of the GS that occurs during AMOC intensification in this regime, which displaces the maximum baroclinicity southward in the jet exit region. We speculate that the mode could not be detected in the MCA with the AMOC because the upper-ocean heat content footprint of the AMOC evolves rapidly in this regime, reflecting the progressive penetration of heat content anomalies into the subpolar gyre. Indeed, the upper heat content pattern detected in the seasonal analysis only resembles the AMOC footprint at zero lag. Since the MCA between AMOC and SLP is dominated at zero lag by the AMOC response to the atmosphere, its back interaction on the atmosphere is masked and cannot be detected without lagging the AMOC, which alters its heat content footprint. A winter mode is also found using SST in the seasonal analysis, but with somewhat different patterns, suggesting that the wintertime climatic impact of the AMOC lacks robustness. Nonetheless, if an AMOC intensification is forcing a negative NAO in this regime, it would act as a weak negative feedback, thus reducing the AMOC time scale and favoring the oscillatory behavior. Note that Teng et al. (2011) also found that an AMOC intensification tends to drive a negative NAO in winter in the lower-resolution T42 CCSM3 that also has a strong 20 -yr variability. In the oscillatory regime, a significant AMOC influence is detected by MCA during fall and summer, when an intensification of the AMOC precedes an east Atlantic pattern-like SLP signal. However, the mode is not detected in the MCA based on either seasonal upper-ocean heat content or SST anomalies. This suggests that the atmospheric response to the AMOC is less robust in the oscillatory regime. Hence, although the $\mathrm{AMOC}$ is more predictable in the oscillatory regime $(-0.5$ autocorrelation at a lag of $11 \mathrm{yr})$ than in the red noise regime (10-yr $e$-folding time), its climate impacts are likely to be more predictable in the red noise regime, where the AMOC influence on the winter NAO is larger and more robust. 
A likely cause for the different atmospheric response to the AMOC in the two regimes is the different SST footprint of an AMOC strengthening along the GS/ NAC front, which evolves from an east-west dipole (southward shift of the GS and northward shift of the NAC) in the oscillatory regime into a monopole (northward shift of both GS and NAC) in the red noise regime. We speculate that the GS link to the AMOC differs in the two regimes because of the different strength of the DWBC when it meets the GS near Cape Hatteras (Fig. 1). In the oscillatory regime, the DWBC is strong and the bottom vortex stretching because of its strengthening may shift the GS south, as discussed by Zhang and Vallis (2007). In the red noise regime, the DWBC is weaker and the vortex stretching is unable to compensate the northward shift caused (in both regimes) near the western flank of the Mid-Atlantic Ridge by its crossing under the NAC. Which regime is more realistic is difficult to ascertain, however, as modeling and observational studies give conflicting results. Indeed, oceanic hindcasts generally show that the GS shifts northward when the AMOC and the subpolar gyre strengthen in response to NAO forcing (e.g., de Coëlogon et al. 2006; Kwon et al. 2010), while in the Geophysical Fluid Dynamics Laboratory Climate Model, version 2.1 (GFDL CM2.1), an AMOC strengthening is associated with a weaker subpolar gyre and a southward GS (Zhang 2008). Joyce and Zhang (2010) give some observational support for the latter relation, but there is little consensus on past AMOC variations or the relation between subpolar gyre and AMOC changes. The different GS shifts influence differently the oceanic heat release to the atmosphere and the low-level baroclinicity in the storm track. In the oscillatory regime, cooling in the GS region shifts the maximum Eady growth rate southward in the jet exit region, but warming along the NAC shifts it northward, resulting in conflicting influence on the growth of transient eddies, although the former effect seems to dominate. In the red noise regime, on the other hand, the low-level maximum baroclinicity is shifted northward all along the GS/NAC, resulting in a more robust impact on the NAO. Our hypothesis of a high sensitivity of the atmosphere in CCSM3 to the meridional shifts of the baroclinicity in the jet exit region needs to be verified, but it seems consistent with the fact that, in CCSM3, the meridional shifts of the storm track in the jet exit are a more prevalent mode of variability than storm-track strengthening (Alexander et al. 2006). However, small changes in the climatology may also contribute to the different atmospheric response in the two regimes, as the GS/NAC is farther south and the surface westerlies slightly weaker in the red noise regime. A high sensitivity to meridional shifts in atmospheric baroclinicity may also explain the lack of robustness of the fall response in the oscillatory regime and the absence of a fall response in the red noise regime, since the SST footprint of the AMOC did not meridionally shift the baroclinicity in this season. In addition, the heat fluxes and the baroclinicity are weaker during fall, so it is expected that the AMOC influence will be weaker. We can also speculate that the limited robustness of the AMOC influence during fall occurs because in the model the maximum eddy growth occurs upstream over land and is thus less sensitive to the AMOC SST footprint. The seasonal change of the mean atmospheric state could also be crucial, as in Peng et al. (1997).

The strong impact of frontal displacements in CCSM3 is also seen locally in the relation between surface wind vorticity and GS/NAC displacement that is consistent with the response of the atmospheric boundary layer to the anomalous crosswind SST gradient. Hence, the quadripolar wind stress curl pattern associated in the oscillatory regime with the AMOC does not reflect the wind stress curl forcing of the subtropical-subpolar gyre boundary, as hypothesized by Danabasoglu (2008), but reflects the local response to the frontal shift covarying with the AMOC.

An influence of AMOC-driven meridional shifts in the low-level baroclinicity was also found in IPSL CM5 and in five other climate models using a loweratmospheric resolution (GF12). However, the winter response to an AMOC intensification was a negative NAO in these models, as the SST footprint of the AMOC was different, resulting in particular in a southward shift of the maximum Eady growth rate, albeit with no obvious link to GS path changes. The mechanism of the atmospheric response thus appears to be similar in each model, but the AMOC influence on the upper ocean may be different. This emphasizes the need to compare the atmospheric response to oceanic forcing with observational evidence. This was done for IPSL CM5 by GDF, who found a good agreement between the winter atmospheric response to North Atlantic SST anomalies in the model and the observed influence of the North Atlantic horseshoe SST anomaly on the NAO in early winter (Czaja and Frankignoul 1999, 2002). A similar comparison indicates that in both CCSM3 regimes, the influence of SST or upper-ocean heat content anomalies on the atmospheric circulation that was detected at the seasonal scale does not compare favorably to the observations because the SST anomaly patterns are strongly influenced in CCSM3 by the meridional shifts of the GS and the NAC, which is not realistic. The discrepancy with the observations is also apparent in the AMO pattern, which in both regimes compares poorly 
to the observed one, as noted by Danabasoglu (2008). Hence, although the AMOC influence on the atmosphere that we have documented for CCSM3 raises the hope that some low-frequency NAO variations might be predictable, in particular in the red noise regime, the signal will not be realistic. This should also be kept in mind when investigating climate changes, stressing the need to test the air-sea interactions in climate models.

Acknowledgments. Support from the NOAA Climate Program Office (Grant Number NA10OAR4310202) and the European Community 7th Framework Programme (FP7 2007-2013) under Grant Agreements GA212643 (THOR) and n.308299 (NACLIM) is gratefully acknowledged. We thank Camille Marini for providing the detrended HadISST data and the reviewers for their thoughtful and constructive comments.

\section{REFERENCES}

Alexander, M. A., U. S. Bhatt, J. E. Walsh, M. S. Timlin, J. S. Miller, and J. D. Scott, 2004: The atmospheric response to realistic Arctic sea ice anomalies in an AGCM during winter. J. Climate, 17, 890-905.

— ability in CCSM3. J. Climate, 19, 2496-2525.

Branstator, G., G. A. Meehl, M. Kimoto, J. R. Knight, M. Latif, and A. M. Rosati, 2012: Systematic estimates of initial value decadal predictability for six AOGCMs. J. Climate, 25, $1827-$ 1846.

Brayshaw, D. J., T. Woollings, and M. Vellinga, 2009: Tropical and extratropical responses of the North Atlantic atmospheric circulation to a sustained weakening of the MOC. J. Climate, 22, 3146-3155.

Chelton, D. B., and Coauthors, 2001: Observations of coupling between surface wind stress and sea surface temperature in the eastern tropical Pacific. J. Climate, 14, 1479-1498.

Cohen, J., M. Barlow, P. J. Kushner, and K. Saito, 2007: Stratospheretroposphere coupling and links with Eurasian land surface variability. J. Climate, 20, 5335-5343.

Collins, M., 2002: Climate predictability on interannual to decadal time scales: The initial value problem. Climate Dyn., 19, 671692.

Collins, W. D., and Coauthors, 2006: The Community Climate System Model version 3 (CCSM3). J. Climate, 19, 2122-2143.

Compo, G. P., and Coauthors, 2011: The Twentieth Century Reanalysis Project. Quart. J. Roy. Meteor. Soc., 137, 1-28.

Czaja, A., and C. Frankignoul, 1999: Influence of the North Atlantic SST on the atmospheric circulation. Geophys. Res. Lett., 26, 2969-2972.

— on the North Atlantic Oscillation. J. Climate, 15, 606-623.

Danabasoglu, G., 2008: On multidecadal variability of the Atlantic meridional overturning circulation in the Community Climate System Model version 3 (CCSM3). J. Climate, 21, 5524-5544.

de Coëtlogon, G., C. Frankignoul, M. Bentsen, C. Delon, H. Haak, S. Massina, and A. Pardaens, 2006: Gulf Stream variability in five oceanic general circulation models. J. Phys. Oceanogr., 36, 2119-2135.
Delworth, T. L., and M. E. Mann, 2000: Observed and simulated multidecadal variability in the Northern Hemisphere. Climate Dyn., 16, 661-676.

Deser, C., R. Thomas, and S. Peng, 2007: The transient atmospheric circulation response to North Atlantic SST and sea ice anomalies. J. Climate, 20, 4751-4767.

Enfield, D. B., A. M. Mestas-Nuñez, and P. J. Trimble, 2001: The Atlantic multidecadal oscillation and its relation to rainfall and river flows in the continental U.S. Geophys. Res. Lett., 28, 2077-2080.

Ferreira, D., and C. Frankignoul, 2005: The transient atmospheric response to midlatitude SST anomalies. J. Climate, 18, 10491067.

Frankignoul, C., and E. Kestenare, 2002: The surface heat flux feedback. Part 1: Estimates from observations in the Atlantic and the North Pacific. Climate Dyn., 19, 633-647.

—, A. Czaja, and B. L'Heveder, 1998: Air-sea feedback in the North Atlantic and surface boundary conditions for ocean models. J. Climate, 11, 2310-2324.

Gastineau, G., and C. Frankignoul, 2012: Cold-season atmospheric response to the natural variability of the Atlantic meridional overturning circulation. Climate Dyn., 39, 3757.

— F. D'Andrea, and C. Frankignoul, 2012: Atmospheric response to the North Atlantic Ocean variability on seasonal to decadal time scales. Climate Dyn., 40, 2311-2330, doi:10.1007/ s00382-012-1333-0.

Hoskins, B., and P. J. Valdes, 1990: On the existence of stormtracks. J. Atmos. Sci., 47, 1854-1864.

Joyce, T. M., and R. Zhang, 2010: On the path of the Gulf Stream and the Atlantic meridional overturning circulation. J. Climate, 23, 3146-3154.

Knight, J. R., C. K. Folland, and A. A. Scaife, 2006: Climate impacts of the Atlantic multidecadal oscillation. Geophys. Res. Lett., 33, L17706, doi:10.1029/2006GL026242.

Kwon, Y.-O., and C. Frankignoul, 2012: Stochastically-driven multidecadal variability of the Atlantic meridional overturning circulation in CCSM3. Climate Dyn., 38, 859-876.

- M. A. Alexander, N. A. Bond, C. Frankignoul, H. Nakamura, B. Qiu, and L. A. Thompson, 2010: Role of the Gulf Stream and Kuroshio-Oyashio systems in large-scale atmosphereocean interaction: A review. J. Climate, 23, 3249-3281.

Large, W. G., and G. Danabasoglu, 2006: Attribution and impacts of upper-ocean biases in CCSM3. J. Climate, 19, 23252346.

Levitus, S., T. Boyer, M. Conkright, D. Johnson, T. O’Brien, J. Antonov, C. Stephens, and R. Gelfeld, 1998: Introduction. Vol. 1, World Ocean Database 1998, NOAA Atlas NESDIS $18,346 \mathrm{pp}$.

Marini, C., and C. Frankignoul, 2013: An attempt to deconstruct the Atlantic multidecadal oscillation. Climate Dyn., doi:10.1007/ s00382-013-1852-3, in press.

Msadek, R., and C. Frankignoul, 2009: Atlantic multidecadal oceanic variability and its influence on the atmosphere in a climate model. Climate Dyn., 33, 45-62.

- , K. W. Dixon, T. L. Delworth, and W. Hurlin, 2010: Assessing the predictability of the Atlantic meridional overturning circulation and associated fingerprints. Geophys. Res. Lett., 37, L19608, doi:10.1029/2010GL044517.

O'Neill, L. W., D. B. Chelton, and S. K. Esbensen, 2010: The effects of SST-induced horizontal surface wind speed and direction gradients on midlatitude vorticity and divergence. J. Climate, 23, 255-281. 
Peng, S., W. A. Robinson, and M. P. Hoerling, 1997: The modeled atmospheric response to midlatitude SST anomalies and its dependence on background circulation states. J. Climate, 10, 971-987.

,-- S. Li, and M. P. Hoerling, 2005: Tropical SST forcing of coupled North Atlantic seasonal responses. J. Climate, 18, 480-496.

Pohlmann, H., M. Botzet, M. Latif, A. Roesch, M. Wild, and P. Tschuck, 2004: Estimating the decadal predictability of a coupled AOGCM. J. Climate, 17, 4463-4472.

Rayner, N. A., D. E. Parker, E. B. Horton, C. K. Folland, L. V. Alexander, D. P. Rowell, E. C. Kent, and A. Kaplan, 2003: Global analysis of sea surface temperature, sea ice, and night marine air temperature since the late nineteenth century. J. Geophys. Res., 108, 4407, doi:10.1029/2002JD002670.

Small, R. J., and Coauthors, 2008: Air-sea interaction over ocean fronts and eddies. Dyn. Atmos. Oceans, 45, 274-319.

Steele, M., R. Morley, and W. Ermold, 2001: PHC: A global ocean hydrography with a high-quality Arctic Ocean. J. Climate, 14, 2079-2087.

Stouffer, R. J., and Coauthors, 2006: Investigating the causes of the response of the thermohaline circulation to past and future climate changes. J. Climate, 19, 1365-1387.
Sutton, R. T., and D. L. R. Hodson, 2005: Atlantic Ocean forcing of North American and European summer climate. Science, 309, 115-118.

Teng, H., G. Branstator, and G. Meehl, 2011: Predictability of the Atlantic overturning circulation and associated surface patterns in two CCSM3 climate change ensemble experiments. J. Climate, 24, 6054-6076.

Tulloch, R., and J. Marshall, 2012: Exploring mechanisms of variability and predictability of Atlantic meridional overturning circulation in two coupled climate models. J. Climate, 25, 4067-4080.

von Storch, H., and F. W. Zwiers, 1999: Statistical Analysis in Climate Research. Cambridge University Press, $342 \mathrm{pp}$.

Woollings, T., J. M. Gregory, J. G. Pinto, M. Reyers, and D. J. Brayshaw, 2012: Response of the North Atlantic storm track to climate change shaped by ocean-atmosphere coupling. Nat. Geosci., 5, 313-317.

Zhang, R., 2008: Coherent surface-subsurface fingerprint of the Atlantic meridional overturning circulation. Geophys. Res. Lett., 35, L20705, doi:10.1029/2008GL035463.

_ , and G. K. Vallis, 2007: The role of bottom vortex stretching on the path of the North Atlantic western boundary current and on the northern recirculation gyre. J. Phys. Oceanogr., 37, 2053-2080. 